\title{
MANIFESTAÇÕES CULTURAIS DO MUNICIPIO DE VALENTE E PARTICIPAÇÃO FEMIINA
}

\author{
Diana Paula Nunes do Carmo ${ }^{1}$; Acácia Batista Dias² Ildes Ferreira de Oliveira $^{3}$ \\ 1. Bolsista PIBIC/CNPq, Graduanda em Psicologia, Universidade Estadual de Feira de \\ Santana, e-mail: diaananunes@gmail.com \\ 2. Orientadora, Departamento de Ciências Humanas e Filosofia, Universidade Estadual \\ de Feira de Santana, e-mail: acaciabatistadias02@gmail.com \\ 3. Coordenador do Projeto Ser Tão Forte: Desenvolvimento Territorial Sustentável, \\ Departamento de Ciências Humanas e Filosofia, Universidade Estadual de Feira de \\ Santana, e-mail: ildesferreira@gmail.com
}

PALAVRAS-CHAVE: manifestações culturais; grupos culturais; mulheres

\section{INTRODUÇÃO}

Este plano de trabalho faz parte do projeto "SER TÃO FORTE: Desenvolvimento Territorial Sustentável", apoiado pela Chamada CNPq/MDA/SPMPR N ${ }^{\circ} 11 / 2014$ - Núcleos de Extensão em Desenvolvimento Territorial (Processo $\mathrm{CNPq}^{\circ}$ 463080/2014-9). O trabalho aqui desenvolvido objetivou mapear os grupos culturais do município de Valente (BA), destacando àqueles compostos por mulheres, a fim de perceber uma possível influência dessa participação na construção da identidade feminina.

Se tratando de cultura popular, o texto da Organização das Nações Unidas para a Educação, a Ciência e a Cultura (Unesco) é uma referência para os países nas discussões sobre cultura. No documento de $1989^{1}$, registra-se: a cultura tradicional e popular como o conjunto de criações que emanam de uma comunidade cultural fundadas na tradição, expressadas por um grupo ou por indivíduos e que reconhecidamente respondem às expectativas da comunidade enquanto expressão de sua identidade cultural e social; as normas e os valores se transmitem oralmente, por imitação ou de outras maneiras. Suas formas compreendem, entre outras, a língua a literatura, a música, a dança, os jogos, a mitologia, os ritos, os costumes, o artesanato, a arquitetura e outras artes.

No Brasil, na década de 1980 e anos subsequentes, ocorreu um movimento significativo de retomada do interesse por questões culturais de tradição oral, identificadas como culturas popular, tradicional, popular de tradição oral, raiz, tradições populares e também o folclore que é o termo consagrado historicamente. Esses fatos culturais também podem ser caracterizados como patrimônio imaterial, mediante a Constituição Federal de 1988 que engloba como Patrimônio Cultural Brasileiro, os recursos de natureza material e imaterial. (IKEDA, 2013). Nesse contexto de cultura popular e de recursos materiais e imateriais que as manifestações culturais do município de Valente estão inseridas e arraigadas, predominando as danças como Samba de Roda e o Reisado, e para a finalidade do presente relatório a ênfase reside da atuação feminina nesse cenário.

O Samba de Roda foi inspirado nos ritmos tribais africanos e é a junção de um estilo musical associado a uma dança. São utilizados instrumentos como pandeiros, atabaques, berimbau e viola de chocalho seguido de palmas harmoniosas. No samba de

\footnotetext{
${ }^{1}$ Conferência "Recomendação sobre a salvaguarda da cultura tradicional e popular" IN: IKEDA (2013), tradução do autor.
} 
roda, a dança é organizada com uma pessoa no centro da roda, dançando sozinho e realizando gestos no ritmo da música e posteriormente escolhe outra pessoa para assumir seu lugar, com uma umbigada, e assim vão acontecendo as trocas dos dançarinos no centro da roda. A presença das mulheres é fundamental nessa apresentação, elas batem as palmas e frequentemente saem para sambar e para responder aos versos cantados. (OLIVEIRA; AMAZONAS; DORIA, 2010).

Outra manifestação presente na cultura popular é o Reisado, que é descrito por Araújo (1973) como característico da região da jangada, onde alegra as noites das cidades e povoados nordestinos. Os trajes do reisado são os mais vivos por conta de seus vários enfeites de espelhinhos, vidrinhos, lentejoulas, entre outros. Os espelhos têm uma finalidade mágica, funcionam como um amuleto, servindo para um choque de retorno, onde todo o mal e todos os maus desejos que baterem nos espelhos retornarem para quem os tenha tido. A função desses espelhos é protetiva, defensiva e amulética. As danças são denominadas de peças, onde são executados os mais determinados passos e aparece a criação individual dos dançarinos.

\section{MATERIAL E MÉTODOS}

Para o desenvolvimento dessa pesquisa foram feitas consultas a referências bibliográficas leituras e fichamentos para compreensão e desenvolvimento do tema. Foram realizadas entrevistas semiestruturadas com mulheres participantes dos grupos culturais, com a Representante Territorial de Cultura (RTC) que é uma agente institucional da SECULT, representantes institucionais como a ex- secretária de cultura do município e o ex-prefeito para a obtenção de informação do mapeamento dos grupos culturais, compreensão da forma como as atividades eram desenvolvidas, como ocorreu o processo de formação dos grupos, contexto e as principais motivações e as políticas públicas do território.

\section{RESULTADOS E/OU DISCUSSÃO}

A partir do mapeamento realizado sobre os grupos culturais do município de Valente, foram encontrados quatro grupos culturais com participação feminina, sendo estes: (i) As Cantadeiras do Sisal e Aboiadores de Valente, (ii) Reisado, (iii) Samba de Roda e (iv) Cantiga de Roda de Valente.

O grupo das Cantadeiras do Sisal e Aboiadores de Valente é um grupo de produção, onde são confeccionados bolsas e tapetes de sisal. O grupo existe há 17 anos, e permaneceu sempre ativo desde a sua criação. É composto por seis mulheres e dois homens, a inserção dos dois Aboiadores se deu quando foram requisitadas para participar do projeto Sonora Brasil. O grupo tem sede fixa, onde acontece a produção e também os ensaios para as apresentações. Durante a produção do artesanato, essas mulheres cantam as cantigas que lhes foram ensinadas por seus pais e que passaram de geração em geração, relembrando o tempo de trabalho como lavradoras.

Os grupos do Reisado e Samba de Roda vão ser descritos conjuntamente porque as informações foram obtidas pela coordenadora, que participa e exerce essa função nos dois grupos simultaneamente. Estes são compostos por praticamente as mesmas pessoas, homens e mulheres, e realizam suas apresentações geralmente juntas. A entrevistada não sabia exatamente o número de homens e mulheres que faziam parte do grupo. O reisado tem a participação de homens idosos e as apresentações acontecem na maioria das vezes, juntamente com as mulheres do Samba de Roda, que também fazem parte do grupo do Reisado. Os grupos têm mais ou menos 50 anos de existência e não recebem nenhum tipo de remuneração nas suas apresentações, apenas auxílio da 
prefeitura com transporte e materiais utilizados para decoração durante as apresentações.

O grupo Cantiga de Roda de Valente existe desde a década de 1970 e é composto por mulheres, homens e crianças, sendo que a entrevistada não sabia o número de participantes no total, ela atua do grupo desde pequena, mas não sabe especificar o período da formação do mesmo. O trabalho do grupo é também realizado com crianças, através de oficinas nas escolas e nos povoados no entorno de Valente. Eles fazem as apresentações de samba e de reisado e as crianças se apresentam junto com eles, alguns tocam instrumentos e outros compõem os versos.

Quando as entrevistadas foram questionadas a respeito de suas inserções e participações nos grupos, relataram que a decisão ocorreu motivada pelo desejo de se sentirem úteis, ativas e pertencentes às atividades culturais. Afirmaram que apesar das dificuldades que encontram mediante aos problemas que surgem no cotidiano, estar no grupo é uma forma de enfretamento e superação.

Estas descrevem ao longo das entrevistas sentimentos de reconhecimento do seu trabalho, melhora de autoestima e qualidade de vida, o desejo de se sentirem úteis, ativas e pertencentes a algo que as motivaram a fazer parte e permanecer nos grupos culturais, podem ser vistos na literatura através dos estudos de Ryan e Deci (2001) sobre o bem-estar, organizado em duas categorias: o subjetivo, que aborda o estado subjetivo da felicidade; e o psicológico, que investiga o potencial humano.

A participação das mulheres de uma forma geral na cultura do município de Valente foi avaliada como atuante, por estarem sempre presentes e disporem de uma facilidade maior para se organizar na realização dos eventos. Porém, um dos fatores unânimes descritos por essas mulheres, foi a falta de uma pessoa que gerenciasse as questões culturais e estivesse à frente da organização e realização desses eventos, como pode ser visto no relato de uma participante do grupo Samba de Roda: Falta um incentivo, uma pessoa ter um cargo pra dizer assim eu vou botar a cultura pra lá, pra funcionar, mais e mais, porque muitas vezes quando é tempo de funcionar uma coisa, bota uma pessoa que não tem aquele aprendizado... (M.O, 64 anos, grupo Samba de roda, participa do grupo há nove anos.)

Assim como as participantes do grupo, a Representante Territorial de Cultura do município e a ex-secretária sinalizaram questões de falta de investimento na cultura por parte dos gestores, principalmente pelo fato de não ser uma condição importante para obtenção de votos numa futura eleição. [...]E aí esse gestor não fomenta aquilo que é subjetivo, porque na cabeça dele a cultura não dá voto, e eu já ouvi isso de um prefeito, pra que a gente vai fazer uma semana de cultura se cultura não dá voto, melhor você fazer um São João, um pagode...” (N.E, 30 anos, Representante Territorial de Cultura)

As políticas públicas destinadas à cultura no Território do Sisal, de acordo com a RTC, são os programas de Cultura Viva e os Pontos de Cultura. A Política Nacional de Cultura Viva foi criado em 2014, para assegurar a ampliação do acesso da população aos meios de produção, circulação e desfrute cultural, por meio do Ministério da Cultura, em parceria com os governos estaduais e municipais, além de escolas e universidades, essa política se tornou bastante conhecida através do projeto Pontos de Cultura. 
Em contrapartida a essa realidade, especificamente no município de Valente, a ex-secretária de cultura, relata não existir políticas culturais atuantes no período em que ela estava à frente da Secretária de Cultura. [...]A gente não tem na verdade fundo de cultura. Porque a lei de cultura do município, ela foi sancionada, aprovada, ta tudo certinho.... mas, ela não foi implementada, porque pra isso precisa-se que o gestor tenha interesse em fazer acontecer $e$ deposite um percentual do orçamento para cultura..." (E.S, 36 anos, Ex-Secretária de Cultura do Município).

\section{CONSIDERAÇÕES FINAIS}

A partir das informações coletadas, pode-se perceber a dificuldade da construção do conceito de cultura por mulheres que fazem parte de grupos culturais do município de Valente. A cidade apesar de ter um histórico rico culturalmente, atualmente se encontra sem investimentos e sem valorização da cultura por parte dos gestores e também pela população local, que parece não apreciar as manifestações culturais da terra. Apesar desse contexto, a motivação das mulheres para a participação dos grupos independe disso, por conta dos sentimentos de realização pessoal, enfretamento das situações do cotidiano e superação das mesmas.

No que tange as políticas públicas e aos investimentos para a cultura do município, foram relatados na maioria das vezes como inexistentes e ineficazes, sendo esse um ponto unânime descrito pelas as mulheres e pelas pessoas institucionais entrevistadas. Isso se deu principalmente por falta de interesse dos gestores e dos responsáveis para que pudessem desenvolver e organizar atividades voltadas para a promoção de manifestações culturais no município.

\section{REFERÊNCIAS}

GERTZ, Clifford. A interpretação das culturas- 1ed, Rio de Janeiro, 1926.

Ryan, R. M. \& Deci, E. L. (2001). On happiness and human potentials: A review of research on hedonic and eudaimonic well being. Annual Review of Psychology, 52, 141-166.

IKEDA, Alberto T. Culturas populares no presente: fomento, salvaguarda e devoração. Estud. av, São Paulo, v.27, n.79, 2013. 